\title{
Construction and functional study of pGN, a mammary gland-specific expression plasmid
}

\author{
J. Lin, Q.H. Yu, Q. Zhang and Q. Yang
}

Key Laboratory of Animal Physiology and Biochemistry, Ministry of Agriculture, Nanjing Agricultural University, Weigang, Nanjing, Jiangsu, China

Corresponding author: Q. Yang

E-mail: zxbyq@njau.edu.cn

Genet. Mol. Res. 13 (2): 4057-4070 (2014)

Received November 21, 2012

Accepted July 10, 2013

Published May 30, 2014

DOI http://dx.doi.org/10.4238/2014.May.30.1

\begin{abstract}
The aim of this study was to construct a mammary glandspecific expression vector, $\mathrm{pGN}$, and to validate its function in expressing growth hormone (GH) both in vitro and in vivo. First, the GH gene was amplified and inserted downstream of the $\beta$-casein 5 '-arm. Next, the neo gene was cloned downstream of the $\beta$-casein 3 '-arm as a selection marker. To analyze the bioactivity of the pGN plasmid, we expressed pGN in a Bcap-37 cell line and in the goat mammary gland. Quantitative PCR analysis revealed that the expression of GH mRNA in the pGN-transfected group was higher than that of the control group in Bcap-37 cells. Results of a radioimmunoassay and an enzyme-linked immunosorbent assay demonstrated that the pGN-transfected group expressed much more GH protein than the non-transfected group $(\mathrm{P}<0.05)$. Upon injection of the pGN plasmid into the goat mammary gland, GH mRNA and growth hormone receptor mRNA expressions increased 2-fold. In vivo analyses revealed that $\mathrm{GH}$ protein expression was higher in the injected group than in the control group. Together, these results strongly demonstrated that the pGN plasmid was constructed correctly and exhibited favorable bioactivity in efficiently expressing GH both in vitro and in vivo.
\end{abstract}

Key words: Growth hormone; pGN plasmid; Bcap-37 cell line; Goat mammary gland 


\section{INTRODUCTION}

Transgenic technology is a promising way to enhance the performance of mammary glands. An essential component to breeding favorable varieties is the selection of the right target gene. Growth hormone $(\mathrm{GH})$, which is synthesized and secreted from the anterior pituitary gland, is an ideal choice as a target as it can stimulate cell growth, reproduction, regeneration, and further influences the secreting cells of the goat mammary gland. GH has been shown to upregulate $\beta$-casein, $\alpha$ S1-casein, $\alpha$ S2-casein, and $\alpha$-lipoic acid mRNA expression in lactating bovine mammary tissues (Yang et al., 2005; Zhou et al., 2008). Furthermore, Capuco et al. (2001) demonstrated that bovine somatotropin increases the rate of cell renewal in lactating mammary glands. GH is effective in stimulating the secretion of insulin-like growth factors (IGF-1) when delivered to cell membranes, thus facilitating the interaction with GH receptors. Boutinaud and Jammes (2004) demonstrated that GH also appears to increase the expression of Stat5 and Stat1 in lactating goat mammary glands.

The mechanism of increased milk production by GH stimulation is well studied. GH influences mammary gland development through its effect on nutrient partitioning and maintains mammary cell function. On the one hand, the galactopoietic response to GH may be a consequence of elevated blood flow, which increases the supply of rate-limiting metabolic substrates to mammary glands (Mepham et al., 1984). On the other hand, GH can bind to high-affinity receptors in the mammary matrix, working on mammary epithelial cells by motivating the paracrine secretion signal pathway to promote the formation of the mammary duct (Shamay et al., 1988).

GH has been extensively utilized in farm agricultural practices, which primarily involves time-consuming and laborious subcutaneous or direct muscle injections of GH in animals. Transgenic technology has recently been employed to create animal lines with new genes inserted into their chromosomes. The ability to modify mammary gland function with transgenic technology provides an opportunity to enhance the performance of GH expression. For example, the production of recombinant human GH reached $5.0 \mathrm{mg} / \mathrm{mL}$ in the milk of cloned transgenic cows (Salamone et al., 2006). Transgenic technology can shorten the breeding period and maintain desired genetic traits more efficiently than conventional breeding methods. However, although many studies have addressed fundamental and applied aspects of expressing additional proteins in mammary glands, the bulk of this research has focused on biomedical, rather than agricultural, applications.

The present study analyzed the feasibility of using transgenic technology as an alternative method for improving GH expression levels. The aim of our research was to construct a mammary gland-specific expression vector, $\mathrm{pGN}$, and to validate its function in cells and mammary glands. The regulatory elements of milk protein, such as $\beta$-lactoglobulin, $\alpha$ S1-casein, $\beta$-casein (Lee et al., 1996; Zinovieva et al., 1998), whey acid protein (Limonta et al., 1995), and lactalbumin (Su and Cheng, 2004) are all widely used in transgenic animals. The vector $\mathrm{pBC} 1$ contains a $\beta$-casein promoter as a regulatory element to initiate $\mathrm{GH}$ protein expression in cells and mammary glands (Bevilacqua et al., 2006). The high bioactivity of the pGN plasmid provides a solid foundation for further study of GH genetically modified goats. 


\section{MATERIAL AND METHODS}

\section{Materials and reagents}

The pBC1 plasmid was generously donated by Professor Cheng of Yangzhou University (originally obtained from Invitrogen). $\mathrm{pBC} 1$ is a mammary gland-specific expression vector, containing a goat $\beta$-casein promoter and a cloning site, which was fitted for expression on mammary gland epithelial cells. This vector has been widely used in the generation of transgenic mice, goats, and cattle.

Pituitary gland samples were collected from Saanen dairy goats. The pCDNA3.1 plasmid (Invitrogen) and the human breast cancer cell line, Bcap-37, were provided by Professor Wang of Nanjing Agricultural University. Goat mammary epithelial cells (GMECs) were isolated and cultured in our laboratory. The JM 109 strain of Escherichia coli was maintained in our laboratory.

\section{Construction of the pGN plasmid}

\section{Amplification of the gh gene}

The full-length of the goat $g h$ (GenBank ID: Y00767) coding sequence (cDNA) was $654 \mathrm{bp}$. Total RNA was extracted from the pituitary gland with Trizol reagent. cDNA was then synthesized with total RNA as a template. Polymerase chain reaction (PCR) amplification was performed with the cDNA template, rTaq polymerase, $10 \mathrm{X}$ buffer, and primers. Parameters for PCR were as follows: $94^{\circ} \mathrm{C}$ for $5 \mathrm{~min}, 94^{\circ} \mathrm{C}$ for $30 \mathrm{~s}, 57^{\circ} \mathrm{C}$ for $30 \mathrm{~s}$, and $72^{\circ} \mathrm{C}$ for $50 \mathrm{~s}$ for 30 cycles, with a final extension at $72^{\circ} \mathrm{C}$ for $10 \mathrm{~min}$. The PCR product was linked to the pMD19-T plasmid and then sequenced. The linked vector was named pMD19-T-gh. PCR primers are listed in Table 1.

Table 1. PCR primers of $g h$ and neo genes.
\begin{tabular}{lllr}
\hline Gene & Sense primer & Anti-sense primer & Product length (bp) \\
\hline$g h$ & CTCGAGATGATGGCTGCAGGCCCCCGGA & CTCGAGCTAGAAGGCACAGCTGGCCTCCCCG & 654 \\
neo & GCGGCCGCTGTGGAATGTGTGTCAGTTA & GCGGCCGCACAGACATGATAAGATACAT & 1521 \\
\hline
\end{tabular}

\section{Amplification of the neo gene}

The full-length of the neo gene was $1521 \mathrm{bp}$, including its promoter and polyA tail. PCR amplification was performed with the plasmid template (plasmid pcDNA3.1), PrimeSTAR $^{\circledR}$ HS DNA polymerase, $10 \mathrm{X}$ buffer, and primers. Parameters for PCR were as follows: $94^{\circ} \mathrm{C}$ for $5 \mathrm{~min}, 94^{\circ} \mathrm{C}$ for $30 \mathrm{~s}, 64^{\circ} \mathrm{C}$ for $30 \mathrm{~s}$, and $72^{\circ} \mathrm{C}$ for $100 \mathrm{~s}$ for 30 cycles, with a final extension at $72^{\circ} \mathrm{C}$ for $10 \mathrm{~min}$. The PCR product was linked to the pMD19-T plasmid and then sequenced. The linked vector was named pMD19-T-neo. All PCR primers are listed in Table 1.

\section{Construction of the pGN plasmid}

The $\mathrm{pBC} 1$ plasmid has been widely used in the generation of transgenic mice (Wang 
et al., 2011), goats (Zhang et al., 2008), and cattle (van Berkel et al., 2002). First, we inserted the $g h$ fragment (digested from pMD19-T-gh with XhoI) into the XhoI cloning site of $\mathrm{pBC} 1$, resulting in the $\mathrm{pBC} 1-g h$ vector. Then, we linked the neo fragment (digested from pMD19-T-neo with NotI) with the pBC1-gh vector at the NotI site to obtain the final vector, pGN. PCR and restriction enzyme digestion methods were used to verify our recombinant plasmid pGN.

\section{Expression of the recombinant plasmid pGN in Bcap-37 cells}

\section{Bcap-37 cell culture}

The Bcap-37 cell line is a human breast cancer cell line that is suitable for investigating mammary gland expression. Quantitative PCR assays were performed to confirm whether the pGN plasmid could be successfully expressed in the Bcap-37 cell line. Bcap-37 cells were grown to confluence on 6-well plastic cell culture plates (Corning) with a medium composed of Dulbecco's modified Eagle's medium (DMEM), 10\% fetal bovine serum (FBS), 100 IU/mL penicillin-G, and $100 \mu \mathrm{g} / \mathrm{mL}$ streptomycin sulfate at $37^{\circ} \mathrm{C}$ in a humidified atmosphere of $5 \%$ $\mathrm{CO}_{2}$. Once the Bcap- 37 cells reached $85 \%$ confluence, they were starved for $24 \mathrm{~h}$ with DMEM only, washed twice with phosphate-buffered solution, and $4 \mu \mathrm{g}$ pGN plasmid was transfected into each well manually.

\section{GH mRNA, GHR mRNA, and GH protein expression}

Quantitative PCR assays were performed to confirm whether the pGN plasmid could be expressed in Bcap-37 cells. Cells were divided into 3 groups $6 \mathrm{~h}$ after transfection: blank group (without transfection), pGN group (transfected with the pGN plasmid), and control group (transfected with the $\mathrm{pBC} 1$ plasmid). Total RNA of the different groups was extracted with Trizol reagent. At least 3 technical (quantitative PCR) replicates were performed for each group. Gene-specific primers were designed using the Primer Express software (Applied Biosystems), and primer sequences are listed in Table 2. The levels of GH expression in the Bcap37 cell lysate and culture medium were measured at 24, 36, 48, and $60 \mathrm{~h}$ with enzyme-linked immunosorbent assay (ELISA) using the Goat Growth Hormone ELISA Kit (NovaTeinBio).

\begin{tabular}{|c|c|c|c|}
\hline Gene & Sense primer & Anti-sense primer & Product length (bp) \\
\hline$\overline{\mathrm{GH}}$ & gagaagctgaaggacctgga & tacgtctccgtcttgtgcag & 194 \\
\hline GHR & gagattcatgecgacatcct & gtgtttcgttgtcgggttct & 215 \\
\hline IGF-1 & atgecagtcacatcctcctc & ctccagcetcctcagatcac & 249 \\
\hline IGF-1R & cgtctgtgaacccggagtat & tctcaggctcatccttgacc & 162 \\
\hline Goat $\beta$-actin & ggcaccacaccttctacaacg & tccttgatgtcacggacgatt & 400 \\
\hline Bcap-37 $\beta$-actin & gatcattgctcctcetgagc & tgtggacttgggagaggact & 385 \\
\hline
\end{tabular}

\section{Expression of the GH protein by radioimmunoassay $(R I A)$}

Bcap-37 cells were seeded at $1 \times 10^{6}$ cells per well on a flat-bottomed 6-well plate 24 $\mathrm{h}$ prior to the experiment. Transfection was performed with the pGN plasmid by liposome. 
Cells were divided into 3 groups $6 \mathrm{~h}$ after transfection: control group (without transfection), transfection group (transfected with the pGN plasmid only), and transfection and induction group (transfected with pGN and induced with $10 \mu \mathrm{g} / \mathrm{mL}$ insulin, $1 \mu \mathrm{g} / \mathrm{mL}$ prolactin, and 20 $\mu \mathrm{g} / \mathrm{mL}$ hydrocortisone).

The levels of GH expression in the Bcap-37 cell lysate and culture medium were measured separately at $12,24,36$, and $48 \mathrm{~h}$ by RIA using the $125 \mathrm{I}-\mathrm{HGH}$ kit (Sinoukbio, Beijing). One hundred microliters of cell lysate and culture medium were mixed with $0.4 \mathrm{~mL} 2 \mathrm{M}$ hydrochloric acid: $95 \%$ ethanol (87.5:12.5), set at room temperature for $30 \mathrm{~min}$, and then centrifuged at $3000 \mathrm{rpm}$ for $30 \mathrm{~min}$ at $4^{\circ} \mathrm{C}$. After centrifugation, $0.2 \mathrm{~mL}$ supernatant was mixed with $0.2 \mathrm{~mL}$ $0.855 \mathrm{M}$ Tris solution for $30 \mathrm{~min}$ at $4^{\circ} \mathrm{C}$ and centrifuged at $3000 \mathrm{rpm}$ for $20 \mathrm{~min}$ at $4^{\circ} \mathrm{C}$. Subsequently, $100 \mu \mathrm{L}$ of the supernatant was aspirated for testing. One hundred microliters of each cell lysate or culture medium extract (or standards), HGH anti-serum, and ${ }^{125} \mathrm{I}-\mathrm{HGH}$ were pipetted into duplicate RIA tubes. Tubes were vortexed and incubated with rotation at $4^{\circ} \mathrm{C}$ for $48 \mathrm{~h}$. At the end of the incubation period, $500 \mu \mathrm{L}$ of the separation reagent was added to each tube followed by a 30-min incubation at room temperature. The tubes were then centrifuged at $3600 \mathrm{rpm}$ for 20 min at $4{ }^{\circ} \mathrm{C}$ to separate the bound and unbound ${ }^{125} \mathrm{I}-\mathrm{HGH}$. Immediately after centrifugation, the supernatant was removed by aspiration. All RIA tubes were then placed in a Beckman Gamma 4000 counter, and the bound ${ }^{125} \mathrm{I}-\mathrm{HGH}$ fraction radioactivity was counted for $2 \mathrm{~min}$ per tube.

\section{Expression of the recombinant plasmid pGN in goat mammary glands}

\section{Plasmid perfusion}

Nine healthy goats were divided into 3 groups: blank group (lactating goat injected with saline), control group (lactating goat injected with the $\mathrm{pBC} 1$ plasmid), and injection group (lactating goat injected with the pGN plasmid). Four hundred micrograms of plasmid pGN was dissolved in $2 \mathrm{~mL}$ saline and injected into the left side of the mammary gland lobule of each experimental goat. The injection was performed in 4 different parts around the mammary gland. We then collected $10 \mathrm{~mL}$ milk after 4, 8, 12, 24, and $36 \mathrm{~h}$. After $36 \mathrm{~h}$, mammary gland tissues of each group were collected and maintained at $-20^{\circ} \mathrm{C}$ until use in subsequent experiments.

\section{Expression of GH mRNA, GHR mRNA, IGF-1 mRNA, and IGF-1R mRNA in goat mammary glands}

Mammary gland tissues (injected gland lobules) of each group were collected for subsequent testing. The expression of GH mRNA was detected by quantitative PCR. Since GH could be bound to GHR or influenced by the expression of IGF-1, we also detected mRNA expression of GHR, IGF-1, and IGF-1R in goat mammary glands. One hundred milligrams of mammary gland tissue of each group was lysed in $1 \mathrm{~mL}$ RNA lysis reagent (TIANGEN) for RNA extraction. Quantitative PCR assays were performed as described above with the primer sequences listed in Table 2 .

\section{GH protein content in goat mammary glands}

The concentrations of the GH protein in goat mammary glands of different 
experimental groups were measured by ELISA using the Goat Growth Hormone ELISA Kit (NovaTeinBio), following manufacturer protocols. First, $50 \mu \mathrm{L}$ diluted standard was transferred to standard wells, $50 \mu \mathrm{L}$ diluted sample was transferred to sample wells, and then the plate was incubated for $30 \mathrm{~min}$ at $37^{\circ} \mathrm{C}$. After incubation, the plate was washed 5 times, $50 \mu \mathrm{L}$ HRP-conjugated antibody was added to each well, and then the plate was incubated for $30 \mathrm{~min}$ at $37^{\circ} \mathrm{C}$. The plate was then washed 5 times, chromogenic substrates $\mathrm{A}$ and $\mathrm{B}$ were added to each well, and it was incubated for $15 \mathrm{~min}$ at $37^{\circ} \mathrm{C}$. Finally, $50 \mu \mathrm{L}$ stop solution was immediately added to each well to stop the reaction and the optical density was measured at $450 \mathrm{~nm}$ within $15 \mathrm{~min}$.

\section{GH content from milk samples}

The concentration of the GH protein in milk samples from different groups was measured by ELISA using the Goat Growth Hormone ELISA Kit (NovaTeinBio). ELISA assays were performed as described above.

\section{Expression of the recombinant plasmid pGN in GMECs}

\section{Isolation and culture of GMECs}

Mammary gland tissues were obtained from Saanen dairy goats (Capra hircus). GMECs were grown in DMEM/F-12 with $10 \%$ FBS in the presence of $10 \mathrm{kU} / \mathrm{mL}$ penicillin and $100 \mathrm{mg} / \mathrm{mL}$ streptomycin under standard culture conditions $\left(5 \% \mathrm{CO}_{2}, 37^{\circ} \mathrm{C}\right)$. Mammary epithelial cells were cultured according to methods described in Hu et al. (2009). Cells were cultured in induction media for 1 week prior to experiments to promote milk protein and fat synthesis. The induction media contained 1\% Insulin-Transferrin-Selenium supplement (Invitrogen), $5 \mathrm{mg} / \mathrm{mL}$ progesterone (ProSpec, USA), $10^{-7} \mathrm{M}$ hydrocortisone (R\&D Systems, USA), $10 \mathrm{ng} / \mathrm{mL}$ ovine epithelial growth factor (ProSpec), and $5 \mathrm{mg} / \mathrm{mL}$ bovine estradiol (Sigma-Aldrich, USA).

\section{Western blot detection of GH protein expression}

Transfection was performed with the liposome-mediated pGN plasmid. Induction cells were divided into 2 groups $6 \mathrm{~h}$ after transfection: control group (transfected with the $\mathrm{pBC} 1$ plasmid) and the transfection group (transfected with the pGN plasmid). The culture medium was changed to DMEM/F-12 containing 10\% FBS $6 \mathrm{~h}$ after transfection. Cells were collected at $48 \mathrm{~h}$ for subsequent tests. GMECs were lysed with radioimmunoprecipitation assay buffer containing phosphatase and protease inhibitors ( $1 \mathrm{mM}$ phenylmethanesulfonylfluoride) on ice for $30 \mathrm{~min}$. The cell lysate was centrifuged at $14,000 \mathrm{~g}$ for $10 \mathrm{~min}$ at $4^{\circ} \mathrm{C}$. Protein preparations from the supernatant were separated by $4-15 \%$ sodium dodecyl sulfate polyacrylamide gel electrophoresis and transferred to nitrocellulose membranes. Membranes were blocked with Tris-buffered saline with Tween 20, containing 5\% non-fat milk at room temperature for $2 \mathrm{~h}$, incubated with the mouse anti-human GH monoclonal antibody at $4^{\circ} \mathrm{C}$ for $18 \mathrm{~h}$, followed by the rabbit anti-mouse IgG-HRP as a secondary antibody. Protein expression was detected with an enhanced chemiluminescence detection system and $\beta$-actin was used as the loading control. 


\section{Statistical analysis}

Statistical analyses of differences in GH concentration among experimental groups were conducted using the SPSS 17 software. Comparisons between two groups were assessed with the Student $t$-test. One-way analysis of variance with LSD's post hoc analysis was performed to assess differences between more than two groups. Significant differences $(P<0.05)$ are shown in Figures. All data are reported as means \pm standard error of the mean.

\section{RESULTS}

\section{Cloning of $g h$ and neo genes}

Results showed that the $g h$ gene was successfully amplified and cloned into the pMD19-T plasmid (Figure 1A), and the pMD19-T-gh plasmid was digested by the restriction enzyme XhoI. Nucleotide sequencing indicated that the cloned $g h$ gene had $99.9 \%$ homology to the goat $g h$ cDNA (GenBank ID: Y00767). Sequence comparison revealed that a mutation occurred at the 394-bp position, in which a G was substituted by an A nucleotide. Further analysis indicated that this mutation was silent, without any effect on GH expression. Figure $1 \mathrm{~B}$ shows that the neo gene was also successfully amplified and cloned into the pMD19-T plasmid and the plasmid pMD19-T-neo was digested by restriction enzyme NotI. Nucleotide sequencing indicated $100 \%$ homology to the neo gene from pcDNA3.1. Sequence analysis indicated that 1521-bp fragments contained a promoter, the neo gene, and polyA.

A

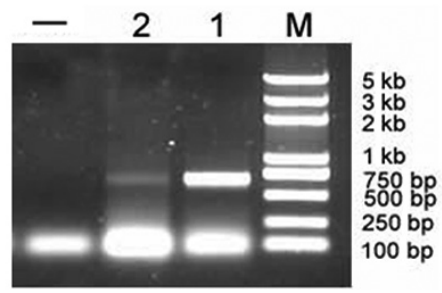

$\mathrm{C}$

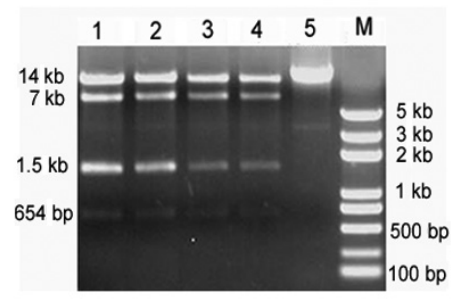

B

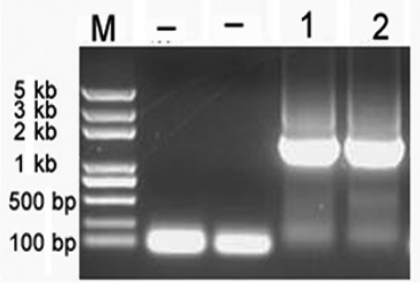

$\mathrm{D}$

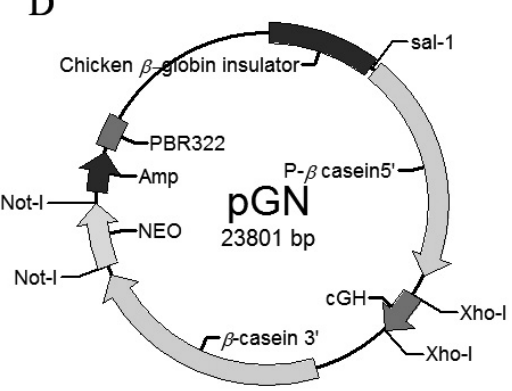

Figure 1. A. GH electrophoresis of PCR product (lanes 1 and $2=g h$; lane $(-)=$ negative clone; lane $M=$ marker DNA/Trans2K Plus). B. neo electrophoresis of PCR product (lanes 1 and 2 = neo; lane $(-)=$ negative clone; lane $M=$ marker DNA/Trans2K Plus). C. Identification of vector $\mathrm{pGN}$ digested with restriction enzymes (NotI/XhoI) (lanes 1, 2, 3, 4 = plasmid pGN-NotI/XhoI; lane $5=$ plasmid pGN; lane $M=$ marker DNA/ $\lambda$-HindIII digest). D. Map of plasmid pGN. 


\section{Identification of the recombinant plasmid pGN}

The recombinant plasmid pGN was cleaved by restriction enzymes NotI and XhoI. After digestion, 4 fragments $(654,152,7135$, and 14,406 bp) were observed (Figure 1C). These results demonstrated that the recombinant plasmid pGN was constructed successfully and the plasmid map is shown in Figure 1D.

\section{Biological activity of the pGN plasmid in Bcap-37 cells}

\section{Expression of GH and GHR $m R N A$}

The pGN plasmid was transfected into Bcap-37 cells with liposome to test its biological activity. The expression of GH mRNA was evaluated by quantitative PCR after $36 \mathrm{~h}$. GH mRNA expression in the transfection group showed a 17-fold increase compared to the control group, demonstrating that the pGN plasmid was successfully transcribed in Bcap-37 cells (Figure 2A). Curiously, GHR mRNA expression was not detected in the control group.

A

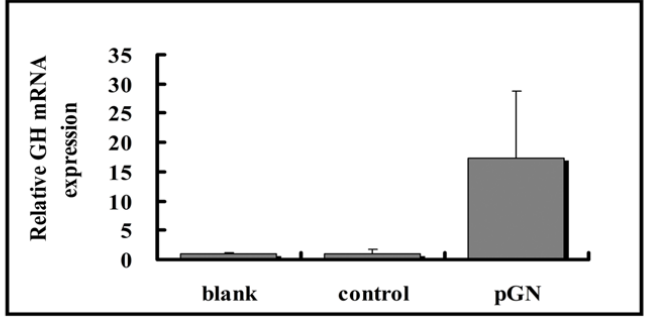

B

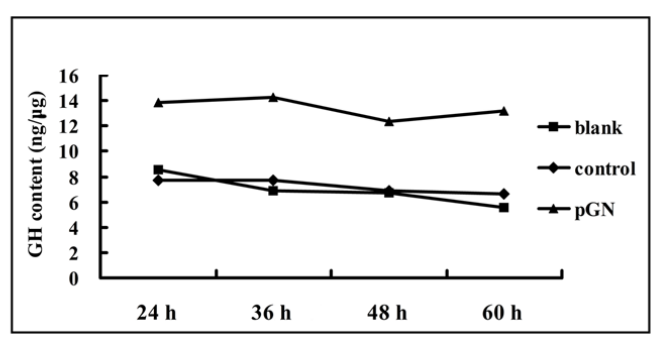

$\mathrm{C}$

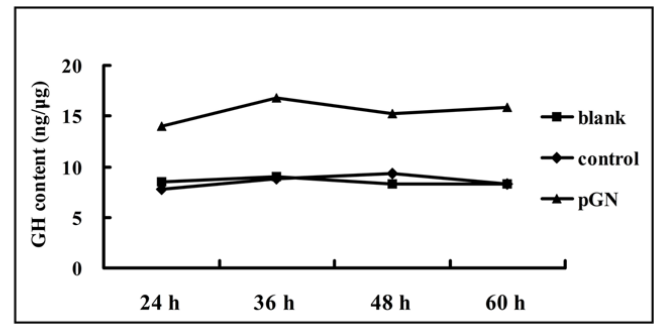

Figure 2. A. Relative GH mRNA expression in Bcap-37 cell line. Bcap-37 cells were divided into three groups 6 $\mathrm{h}$ after transfection: blank group (without transfection), pGN group (transfected with plasmid pGN), and control group (transfected with plasmid pBC1). B. ELISA result of GH content in transfect Bcap-37 cell lysate. C. ELISA result of GH content in transfect Bcap-37 cell culture. 


\section{GH protein expression by RIA and ELISA}

The cell lysate and culture media of different experimental groups were collected to perform RIA analyses to confirm that the GH concentration was upregulated after transfection with the pGN plasmid. Results verified that both the transfection and induction groups expressed much more GH than did the control group. Compared with the control group at 12, 24,36 , and $48 \mathrm{~h}$, the total GH content in the induction group was significantly increased, particularly at $36 \mathrm{~h}(\mathrm{P}<0.05)$. GH expression in the transfection group was somewhat lower than that of the control group at $48 \mathrm{~h}$ (Table $3 \mathrm{~A}$ ). In the cell lysate, the $\mathrm{GH}$ expression increased significantly from $2.12 \pm 0.10 \mu \mathrm{g} / \mathrm{L}(36 \mathrm{~h}$, control group) to $2.73 \pm 0.29 \mu \mathrm{g} / \mathrm{L}$ ( $36 \mathrm{~h}$, induction group) and reached its peak at $2.86 \pm 0.26 \mu \mathrm{g} / \mathrm{L}$ ( $36 \mathrm{~h}$, transfection group) (Table 3B). However, GH expression in the cell culture medium showed a different pattern in which GH expression was higher in the induction group $(3.98 \pm 0.22 \mu \mathrm{g} / \mathrm{L})$ in comparison to that of the control group $(1.90 \pm 0.43 \mu \mathrm{g} / \mathrm{L})$ (Table $3 \mathrm{C})$. Statistical analysis revealed a very large difference in $\mathrm{GH}$ expression between the induction and control group at $36 \mathrm{~h}(\mathrm{P}<0.05)$.

Table 3. Expression of the GH protein by RIA. A. Expression of the GH protein in cell culture medium and cell lysate. B. Expression of the GH protein in cell lysate. C. Expression of the GH protein in cell culture medium.

A.

\begin{tabular}{lcccc}
\hline & $12 \mathrm{~h}$ & $24 \mathrm{~h}$ & $36 \mathrm{~h}$ & $48 \mathrm{~h}$ \\
\hline Control group & $5.32 \pm 0.37$ & $5.35 \pm 0.48$ & $4.3 \pm 0.46$ & $6.00 \pm 0.18$ \\
Transfection group & $5.36 \pm 0.36$ & $5.25 \pm 0.25$ & $5.45 \pm 0.38$ & $5.21 \pm 0.54$ \\
Induction group & $5.82 \pm 0.57$ & $5.96 \pm 0.29$ & $6.13 \pm 0.56^{*}$ & $5.67 \pm 0.28$ \\
\hline
\end{tabular}

\begin{tabular}{lllll} 
B. & & & & \\
\hline Control group & $2.32 \pm 0.26$ & $2.06 \pm 0.44$ & $2.13 \pm 0.10$ & \\
Transfection group & $2.44 \pm 0.16$ & $2.45 \pm 0.48$ & $2.86 \pm 0.26$ & $2.98 \pm 0.34$ \\
Induction group & $2.36 \pm 0.24$ & $2.60 \pm 0.45$ & & \\
\hline C. & & & & $2.46 \pm 0.10$ \\
\hline Control group & $2.83 \pm 0.21$ & $2.99 \pm 0.37$ & $1.90 \pm 0.43$ & \\
Transfection group & $3.34 \pm 0.37$ & $3.01 \pm 0.25$ & $3.19 \pm 0.26$ & $3.84 \pm 0.31$ \\
Induction group & $3.89 \pm 0.30$ & $3.07 \pm 0.23$ & $3.98 \pm 0.22 *$ & $3.05 \pm 0.40$ \\
\hline
\end{tabular}

Data are reported as means $\pm \mathrm{SE}$ in $\mu \mathrm{g} / \mathrm{L}$. Cells were divided into three groups $6 \mathrm{~h}$ after transfection: control group (without transfection), transfection group (transfected with plasmid pGN only), and induction group (transfected with pGN and induced with $10 \mu \mathrm{g} / \mathrm{mL}$ insulin, $1 \mu \mathrm{g} / \mathrm{mL}$ PRL and $20 \mu \mathrm{g} / \mathrm{mL}$ hydrocortisone). *Significant difference $(\mathrm{P}<0.05)$.

The ELISA results of GH content also demonstrated that the pGN plasmid successfully delivered the GH protein in the Bcap-37 cell line. In the cell lysate, GH content of the pGN transfection group $(13.87,14.28,12.31$, and $13.15 \mathrm{ng} / \mu \mathrm{g}$ ) was much higher than that of the control $(7.69,7.72,6.91$, and $6.65 \mathrm{ng} / \mu \mathrm{g})$ and blank $(8.51,6.88,6.74$, and $5.56 \mathrm{ng} / \mu \mathrm{g})$ groups at all times measured (Figure 2B). Similar results were obtained for the cell culture medium (Figure 2C).

\section{Biological activity of the pGN plasmid in goat mammary glands}

\section{mRNA expression of $G H, G H R, I G F-1$, and IGF-1R in goat mammary glands}

To assess the bioactivity of the pGN plasmid in goat mammary glands, we used quan- 
titative PCR to detect the expression of GH mRNA after the pGN plasmid was injected into mammary glands. On the left side (injection side), data analysis showed no obvious differences in GH mRNA expression between the injection group and the control group, whereas expression of GHR mRNA in the injection group was much higher than that of the control group (Figure 3A). Considering the potential for negative feedback regulation, we also examined mRNA expression of IGF-1 and IGF-1R. Results revealed that mRNA expressions of IGF-1 and IGF-1R in the injection group were lower than those of control group, especially for IGF-1R. On the right side (non-injection side), GH mRNA expression did not differ between the injection group and the control group, although GHR mRNA in the injection group was much more highly expressed than that of the control group (Figure 3B). Furthermore, the pGN plasmid injection group expressed more IGF-1R mRNA than the control group on the non-injection side.
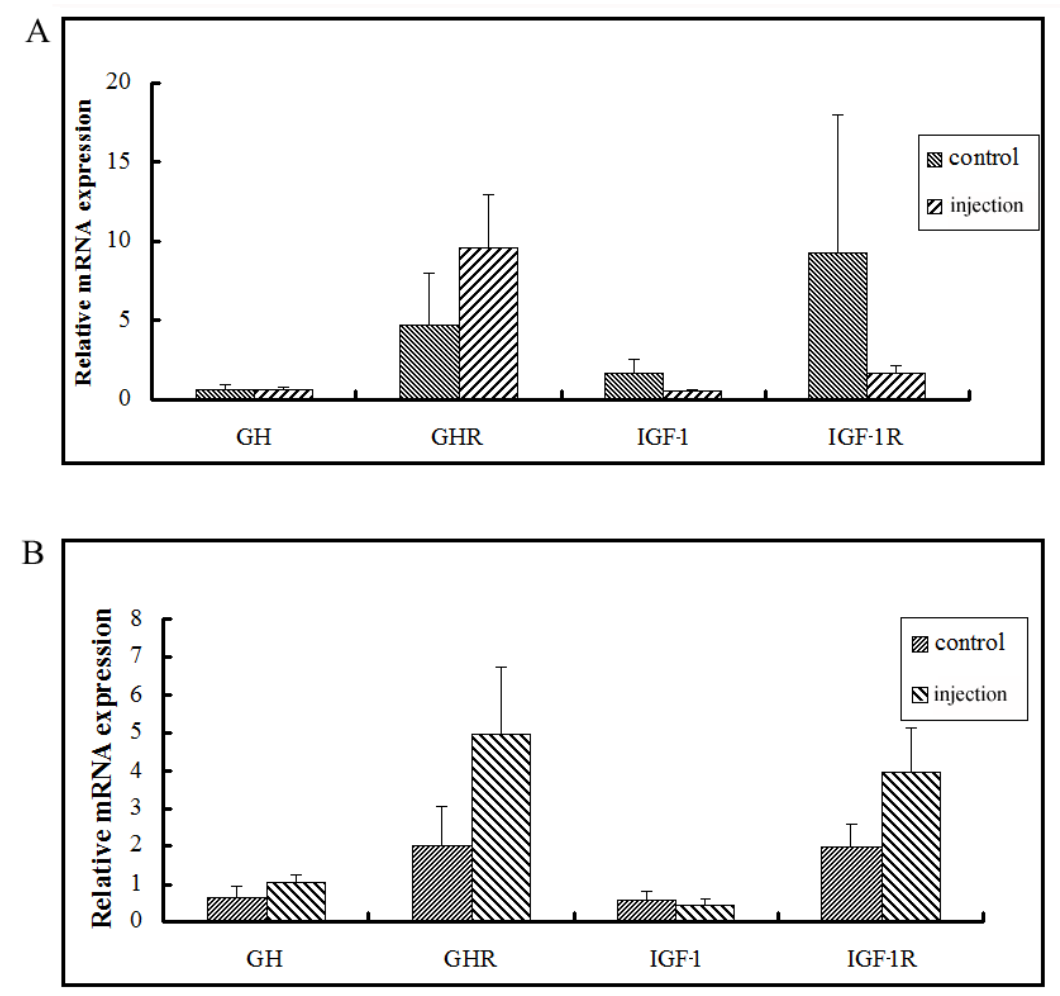

Figure 3. A. Different hormone mRNA expression in the left goat mammary. B. Different hormone mRNA expression in the right goat mammary. Nine healthy goats were divided into three groups: blank group (lactating goat injected with saline), control group (lactating goat injected with plasmid $\mathrm{pBC} 1$ ), and injection group (lactating goat injected with plasmid pGN).

\section{Expression of the GH protein on goat mammary glands by ELISA}

The ELISA analysis showed dramatic differences of GH protein expression in goat mammary glands in the different groups. On the left side (injection side), GH content of the 
injection group $(7.38 \pm 0.14 \mathrm{ng} / \mathrm{mL})$ was higher than that of the control $(6.78 \pm 0.47 \mathrm{ng} / \mathrm{mL})$ and blank $(6.35 \pm 0.06 \mathrm{ng} / \mathrm{mL})$ groups. On the right side (non-injection side), the GH expression decreased from the injection group $(7.34 \pm 0.17 \mathrm{ng} / \mathrm{mL})$ to the control group $(6.62 \pm 0.32$ $\mathrm{ng} / \mathrm{mL})$ and was lowest in the blank group $(6.51 \pm 0.13 \mathrm{ng} / \mathrm{mL})$ (Figure 4A).

\section{Expression of GH in milk samples by ELISA}

Results of ELISA analysis showed no obvious differences in the GH content of milk samples at various times among the various groups sampled. At $0,4,8,12$, and $24 \mathrm{~h}, \mathrm{GH}$ content on the left side (injection side) was $5.41 \pm 0.14,5.30 \pm 0.08,5.14 \pm 0.16,4.68 \pm$ 0.40 , and $5.28 \pm 0.24 \mathrm{ng} / \mathrm{mL}$, respectively, and was $7.18 \pm 0.13,7.30 \pm 0.14,7.10 \pm 0.11$, $6.91 \pm 0.12$, and $6.44 \pm 0.19 \mathrm{ng} / \mathrm{mL}$, respectively, on the right side. Overall, GH content of milk samples increased and fell slightly over time in each group, albeit insignificantly (Figure 4B).
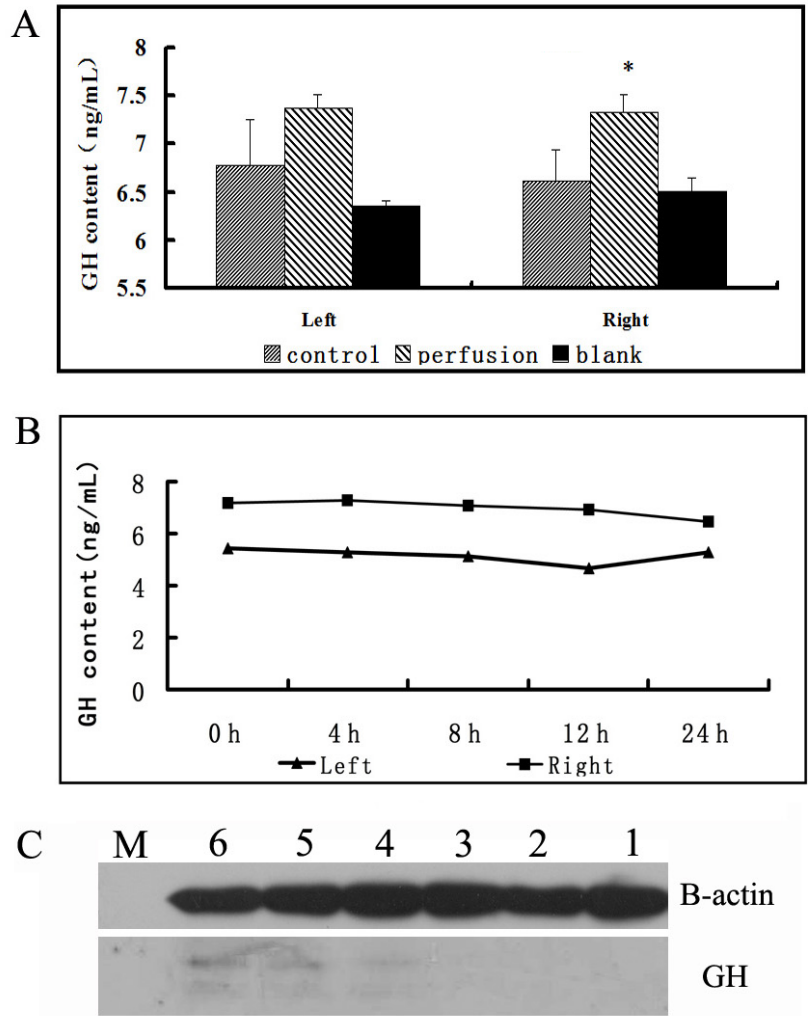

Figure 4. A. GH content in mammary gland. B. GH content in goat milk. Nine healthy goats were divided into three groups: blank group (lactating goat injected with saline), control group (lactating goat injected with plasmid $\mathrm{pBC} 1$ ), and injection group (lactating goat injected with plasmid pGN). C. Western blot detect the expression of $\mathrm{GH}$ on goat mammary epithelial cell (lanes 1,2,3= plasmid pBC1 transfected GMEC; lanes 4, 5, $6=$ plasmid pGN transfected GMEC; lane $M=$ molecular marker). 


\section{Confirmation of the bioactivity of the pGN plasmid in goat mammary epithelial cells by Western blot analysis}

The results of in vitro experiments demonstrated that the pGN plasmid could be expressed in Bcap-37 cells. Since our pGN plasmid was designed to be used in transgenic goats to improve milk production, we transfected the pGN plasmid into GMECs to further evaluate their biology activity (GMECs were verified by immunohistochemical and PCR analyses; data not shown). We found that the GH protein only appeared in the pGN plasmid-transfected group, which convinced us that the pGN plasmid successfully expressed GH on GMECs (Figure 4C).

\section{DISCUSSION}

Transgenic technology is an effective way to breed animal lines with desired traits. To improve milk production, the key factor for transgenic expression lies in the selection of a lactation-related gene and an optimal regulatory element. Recent studies have shown that high level expressions in mammary glands of rats (Lee et al., 1996), sheep (Wright et al., 1991), goats (Parker et al., 2004), and cows (van Berkel et al., 2002) could be obtained by $\beta$-lactoglobulin and $\beta$-casein regulation. Production ability of ruminant mammary glands is generally determined based on the number and activity of secreted cells. GH plays an important role in mammary gland development (Bauman, 1999; Akers, 2006) and lactation (Etherton and Bauman, 1998). GH likely acts specifically on mammary glands by regulating the expression of Stat1, Stat3, and Stat5 (Boutinaud and Jammes, 2004; Boutinaud et al., 2004), or might act directly on mammary epithelial cells to stimulate the transcription of $\beta$-casein genes (Hadsell et al., 2002). Salamone et al. (2006) successfully obtained high-level expression of human GH in the milk of transgenic cows. Since GH could increase milk production without altering lactose, fat, or protein contents (Bauman, 1999), overexpression of GH in goat mammary glands has strong potential for the development of a highly productive line. In this study, we demonstrated expression of a recombinant protein in goat mammary glands injected with a non-viral recombinant plasmid.

To verify the biological function of the mammary-specific expression plasmid pGN, we transfected pGN into Bcap-37 cells (Zhang et al., 2009) and measured GH mRNA and GH protein expression levels. The 17-fold increase in GH mRNA demonstrated that the pGN plasmid could be successfully transcribed in Bcap-37 cell lines. Accordingly, Sakamoto et al. (2005) showed a positive influence of GH on milk protein production in a mammary cell line. After examining mRNA expression, we further evaluated GH protein contents with RIA and ELISA. In the control group, GH increased slowly over time in Bcap-37 cells, implicating different GH domains and 4 casein types (He et al., 2010). In the two treatment groups, GH showed dramatic changes. Initially (at $12 \mathrm{~h}$ ), the transfection and induction groups expressed much more GH than did the control group. The increased expression of GH at $12 \mathrm{~h}$ was primary attributed to the cell cultural medium. Over time, this difference decreased, as the GH contents in the transfection and induction groups were only slightly higher than those of the control group at $24 \mathrm{~h}$. Interestingly, the decline of the GH protein at $24 \mathrm{~h}$ was mainly attributed to the cell lysate. At $36 \mathrm{~h}, \mathrm{GH}$ concentrations in the transfection and induction groups were once again significantly higher than those of the control group $(\mathrm{P}<0.05)$. This result suggested that the GH protein could be maximally expressed at $36 \mathrm{~h}$. At $48 \mathrm{~h}$, total GH expression tended to decrease, particularly in the induction group. This decrease may have been due to nutrient depletion, 
resulting in the lack of raw materials with which to synthesize GH proteins. Nevertheless, it is important to note that in the results of our analyses (qPCR, RIA, and ELISA of Bcap-37 cells), the transfection and induction groups expressed much more GH than the control group.

Despite much speculation of the effect of $\mathrm{GH}$ on lactation in vivo, whether $\mathrm{GH}$ has a direct effect on GHR, IGF-1, or IGF-1R expression remains unclear. Our results of in vivo experiments showed no obvious increase in GH mRNA expression on the injection side that could be attributed to the pGN plasmid. Observations in vivo found that overexpressed GH mRNA was always coupled with high-level expression of GHR mRNA, suggesting that GHR might directly regulate the addition of GH in vivo. As for the non-injection side, the increase in GH and GHR mRNA, whether direct, indirect, or both, would require a coordinated response within the mammary gland. Our results also demonstrated that GH mRNA affected not only GHR mRNA expression but also the abundance of IGF-1 mRNA in the mammary gland. Importantly, the expression of GH mRNA was positively correlated with the expression of GHR mRNA, and was negatively correlated to IGF-1 mRNA expression (Figure 3). Therefore, results of this study indicated that GH, adjusted by GHR, could directly affect mammary gland cells (Johnson et al., 2010). In addition, our results demonstrated that transfection or injection with the pGN plasmid increased the amount of GH mRNA in vitro (Bcap-37 cells) but not in vivo (mammary gland cells). The reason for this difference may be due to differences in the GHR mRNA content, which could greatly influence the GH content, and may play a critical role in its regulation. In vitro (Bcap-37 cells) experiments demonstrated no incremental change in GHR mRNA expression. In contrast, GHR mRNA expression in the injection group changed dramatically which might explain the low improvement of GH content in vivo. Although the GH protein was highly expressed in pGN-injected mammary gland tissues, there was no difference in GH content of milk before and after pGN plasmid injection. These slight changes in GH content in milk may be caused by the gene networks driving mammary protein synthesis during the lactation cycle (Bionaz and Loor, 2011).

The pGN plasmid was successfully expressed in the Bcap-37 cell line and in goat mammary glands. GH mRNA and GH protein expressions both increased significantly in transfected cells and in injected goat mammary glands. Furthermore, our results demonstrated that the increment of GH mRNA in goat mammary glands could be adjusted by GHR or IGF-1. The fact that the GH content in milk samples showed no significant change over time implied that the GH protein could act in mammary gland cells without affecting the GH content of milk. Therefore, our results demonstrated that the constructed pGN plasmid has high bioactivity and would be useful for producing GH genetically modified goats.

\section{ACKNOWLEDGMENTS}

Research supported by grants from the National Animal Transgenic Breeding Grand Project (\#2011ZX08008-004; \#2013ZX08008-004).

\section{REFERENCES}

Akers RM (2006). Major advances associated with hormone and growth factor regulation of mammary growth and lactation in dairy cows. J. Dairy Sci. 89: 1222-1234.

Bauman DE (1999). Bovine somatotropin and lactation: from basic science to commercial application. Domest. Anim. Endocrinol. 17: 101-116. 
Bevilacqua C, Helbling JC, Miranda G and Martin P (2006). Translational efficiency of casein transcripts in the mammary tissue of lactating ruminants. Reprod. Nutr. Dev. 46: 567-578.

Bionaz M and Loor JJ (2011). Gene networks driving bovine mammary protein synthesis during the lactation cycle. Bioinform. Biol. Insights 5: 83-98.

Boutinaud M and Jammes H (2004). Growth hormone increases Stat5 and Stat1 expression in lactating goat mammary gland: a specific effect compared to milking frequency. Domest. Anim. Endocrinol. 27: 363-378.

Boutinaud M, Guinard-Flamenta J and Jammes H (2004). The number and activity of mammary epithelial cells, determining factors for milk production. Reprod. Nutr. Dev. 44: 499-508.

Capuco AV, Wood DL, Baldwin R, Mcleod K, et al. (2001). Mammary cell number, proliferation, and apoptosis during a bovine lactation: relation to milk production and effect of bST. J. Dairy Sci. 84: 2177-2187.

Etherton TD and Bauman DE (1998). Biology of somatotropin in growth and lactation of domestic animals. Physiol. Rev. 78: 745-761.

Hadsell DL, Bonnette SG and Lee AV (2002). Genetic manipulation of the IGF-I axis to regulate mammary gland development and function. J. Dairy Sci. 85: 365-377.

He Z, Zhao Y, Mei G, Li N, et al. (2010). Could protein tertiary structure influence mammary transgene expression more than tissue specific codon usage? Transgenic Res. 19: 519-533.

$\mathrm{Hu} \mathrm{H}$, Wang J, Bu D, Wei H, et al. (2009). In vitro culture and characterization of a mammary epithelial cell line from Chinese Holstein dairy cow. PLoS One 4: e7636.

Johnson TL, Fujimoto BA, Jimenez-Flores R and Peterson DG (2010). Growth hormone alters lipid composition and increases the abundance of casein and lactalbumin mRNA in the MAC-T cell line. J. Dairy Res. 77: 199-204.

Lee CS, Kim K, Yu DY and Lee KK (1996). An efficient expression of human growth hormone (hGH) in the milk of transgenic mice using rat $\beta$-casein/hGH fusion genes. Appl. Biochem. Biotechnol. 56: 211-222.

Limonta JM, Castro FO, Martinez R, Puentes P, et al. (1995). Transgenic rabbits as bioreactors for the production of human growth hormone. J. Biotechnol. 40: 49-58.

Mepham TB, Lawrence SE, Peters AR and Hart IC (1984). Effects of exogenous growth hormone on mammary function in lactating goats. Horm. Metab. Res. 16: 248-253.

Parker MH, Birck-Wilson E, Allard G, Masiello N, et al. (2004). Purification and characterization of a recombinant version of human $\alpha$-fetoprotein expressed in the milk of transgenic goats. Protein Expr. Purif. 38: 177-183.

Sakamoto K, Komatsu T, Kobayashi T, Rose MT, et al. (2005). Growth hormone acts on the synthesis and secretion of $\alpha$-casein in bovine mammary epithelial cells. J. Dairy Res. 72: 264-270.

Salamone D, Baranao L, Santos C, Bussmann L, et al. (2006). High level expression of bioactive recombinant human growth hormone in the milk of a cloned transgenic cow. J. Biotechnol. 124: 469-472.

Shamay A, Cohen N, Niwa M and Gertler A (1988). Effect of insulin-like growth factor I on deoxyribonucleic acid synthesis and galactopoiesis in bovine undifferentiated and lactating mammary tissue in vitro. Endocrinology 123: 804-809.

Su HY and Cheng WT (2004). Increased milk yield in transgenic mice expressing insulin-like growth factor 1. Anim. Biotechnol. 15: 9-19.

van Berkel PH, Welling MM, Geerts M, van Veen HA, et al. (2002). Large scale production of recombinant human lactoferrin in the milk of transgenic cows. Nat. Biotechnol. 20: 484-487.

Wang Y, Tong J, Li S, Zhang R, et al. (2011). Over-expression of human lipoprotein lipase in mouse mammary glands leads to reduction of milk triglyceride and delayed growth of suckling pups. PLoS One 6: e20895.

Wright G, Carver A, Cottom D, Reeves D, et al. (1991). High level expression of active human $\alpha$-1-antitrypsin in the milk of transgenic sheep. Biotechnology 9: 830-834.

Yang J, Zhao B, Baracos VE and Kennelly JJ (2005). Effects of bovine somatotropin on $\beta$-casein mRNA levels in mammary tissue of lactating cows. J. Dairy Sci. 88: 2806-2812.

Zhang J, Li L, Cai Y, Xu X, et al. (2008). Expression of active recombinant human lactoferrin in the milk of transgenic goats. Protein Expr. Purif. 57: 127-135.

Zhang X, Wu Y, Luo F, Su H, et al. (2009). Construction of targeting vector for expressing human GDNF in cattle mammary gland. Appl. Biochem. Biotechnol. 159: 718-727.

Zhou Y, Akers RM and Jiang H (2008). Growth hormone can induce expression of four major milk protein genes in transfected MAC-T cells. J. Dairy Sci. 91: 100-108.

Zinovieva N, Lassnig C, Schams D, Besenfelder U, et al. (1998). Stable production of human insulin-like growth factor 1 (IGF-1) in the milk of hemi- and homozygous transgenic rabbits over several generations. Transgenic Res. 7 : 437-447.

Genetics and Molecular Research 13 (2): 4057-4070 (2014) 